\title{
IUMRS General Assembly Reports on Conferences, Publications
}

The International Union of Materials Research Societies General Assembly Meeting took place in Boston on December 4, 1996, during the 1996 MRS Fall Meeting/ICEM-96 (International Conference on Electronic Materials). IUMRS President M. Doyama from Nishi-Tokyo University presided over the meeting. The IUMRS adhering bodies represented at the meeting included MRS (USA), MexicanMRS, A-MRS (Australia), C-MRS (China), E-MRS (Europe), MRS-J (Japan), MRSKorea, MRS-Russia, and MRS-T (Taiwan). MRS-I (India) representatives were absent. Doyama announced that IUMRS consists of 10 societies, with all continents represented except Africa.

Li Heng-De (MRS-China) has been elected as the 1997 IUMRS vice-president, and Lee Cheng-Gong (MRS-China) has been elected as the 1997 IUMRS secretary. Rodney C. Ewing from the University of New Mexico is the 1997-1998 IUMRS president. He invited representatives to join various committees including business and finance, conferences, communications/publications, electronic website, education, science and technology policy, and strategic planning and programs.

Treasurer G.M. Crean of University College in Cork, Ireland, reported a (projected) net income as of November 16 , 1996 of $\$ 19,550$.

\section{Separate and Joint Conferences Held, 1995-1996}

Various adhering bodies reported on their conferences. A-MRS co-sponsored the Conference on Optoelectronic and Microelectronic Materials and Devices (COMMAD) held December 9-11, 1996 at the Australian National University and co-sponsored one of the symposia at an advanced ceramics conference (PacRim2) held in July 1996 in Cairns. David Johnson of Lucent Technologies was funded by A-MRS as a keynote speaker at the latter conference.

C-MRS reported on four meetings held in Beijing in 1996. The Symposium on R\&D (Research and Development) Trends of Materials, held August 6-8, drew in about 120 attendees to hear 25 speakers. The Symposium on the Importance of Materials in the Development of the National Economy and National Defense, held October 28-30, brought in 80 attendees and 20 speakers. C-MRS Annual Meeting '96 on microstructure analysis and mechanical properties measurement (under special conditions) of materials was held November 17-21, with about 1,000 attendees and 24 symposia.
C-MRS and MRS-K Joint Symposium '96 (in English) was also held November 17-21, with 250 attendees. Symposia topics covered semiconductor materials and epitaxial thin films, magnetic materials, and surfaces and interfaces of materials.

MRS-Korea also held Spring and Fall Meetings in 1996. About 200 scientists attending the Spring Meeting at Kyungpook National University in Taegu, Korea, heard over 139 papers and 11 invited talks on the areas of metallic materials, electronic and magnetic materials, polymers, ceramics, and composite materials. Over 150 papers and three invited talks were presented at the Fall Meeting held at Suwon University in Suwon, Korea, drawing in about 250 attendees.

The E-MRS Spring Meeting, held June 4-7, 1996 at the Palais de Congres in Strasbourg, France, attracted over 1,200 attendees internationally, especially from Japan and the United States. More than 1,240 papers and poster contributions were presented. Since the Palais de Congres served well as a conference site, it will be the location for the ICAM (International Conference on Advanced Materials) '97/E-MRS '97 Spring Meeting (see next section).

E-MRS held two joint conferences in 1996. The joint conference of the First Polish-Ukrainian Symposium on "New Photovoltaic Materials for Solar Cells," organized by R. Cziach in Cracow, was held October 21-22. The joint conference with MRS-Russia on "Radioactive Waste, Storage, Transportation, Recycling, and Human Impact" held in St. Petersburg, Russia, October 14-18, provided a good basis for improving cooperation between Eastern and Western scientists in this field to pave the way to address problems of global importance. About 500 experts from 19 countries, including Central Europe, North and South America, and Asia, participated in the conference. In his keynote speech, MRS-Russia president I.V. Gorynin of Prometey Institute said, "We are the witnesses of how a new scientific trend of the materials science and radioactive waste handling process is being created."

MRS-Russia also held a conference on "Siberian Materials," October 5-6, 1996, in Novosibirsk, Russia, with 290 participants; a conference on "Museum Without Fire," in Riga, Latvia; and the fourth international conference on "Materials Science Aspects in NPP Design, Manufacture, and Operation," in St. Petersburg, bringing together 110 experts, including 28 scientists from the United Kingdom, France, Sweden, Germany, Finland, and South
Korea. MRS-Russia held a number of international seminars during 1995-1996, including "Aging of NPP Materials and Components," "Dissimilar Weldments in NPP Facilities and Pipes: Problems and Solutions," "Assessment of Admissible Defects during NPP Facilities Operation," and one on cellular catalyzers and carriers.

Mexican-MRS hosted ICAM-95 in Cancun, and 850 scientists attended the annual conference of MRS-T, which presented nine symposia and 390 papers. MRS-J held its annual meeting in May 1996, with 1,200 attendees.

\section{Member Societies Prepare for Upcoming Conferences}

IUMRS endorsed the Second International Conference on Low Dimensional Structures and Devices (LDSD97) to be held in Lisbon, Portugal, in May 1997. This conference expects participants representing the global semiconductor industry and academic research from Japan, the Far East, mainland Europe, and USA. MRSKorea will host ICEM-98 and C-MRS will host ICAM-99.

In November 1997, A-MRS, the Australian Institute of Nuclear Science and Engineering, and the Australian Vacuum Society will sponsor a meeting at the Australian National University on the topics of nuclear techniques of analysis, thin films, and surface science. R.G. Elliman will chair the meeting. About 160 participants are expected, including about 50 from Asia and Japan.

E-MRS is hosting ICAM-97, to be held June $16-20$. The program includes 13 symposia, providing a balance of fundamental and applied advanced materials research and development and technology. This meeting is being held in Strasbourg, France and will be the official IUMRS meeting in conjunction with the E-MRS Spring Meeting.

The 1997 MRS Fall Meeting, to be held in Boston on December 1-5, will have 42 symposia. MRS-Russia and C-MRS are preparing a joint symposium on advanced materials to be held in St. Petersburg in June 1997.

The 4th International Union of Materials Research Societies International Conference in Asia (IUMRS-ICA-97) will be held in Makuhari, Chiba, Japan, September 16-18, 1997. The following list of tentative symposia includes experimental and theoretical studies on the various materials, materials characterization, application, and processing: Polymer SurfacesStructure, Property, and Functions; Intelli- 
gent Gel; Polymer Membrane for Environment and Human Body; Polymer Composites; Liquid Crystals and Liquid Crystalline Polymers; Advances in Porous Materials; High Tc Superconductors; Materials Synthesis and Modification by Ion and Laser Beams; Super Carbons; Ferrites: The Science and Technology to New Horizons; Interfaces of Ceramic Materials: Impact on Processing and Properties; New Shaping and Forming Process for New Materials; Soft, Solution Processing for High-Performance Inorganic Materials; Computer-Aided Materials Design and Simulation \& CAMSE-97; Nanomaterials; New Fibers; Thin Films; Perovskite-Related Oxides: Preparation, Properties, and Perspective; Mechanical Properties of High Temperature Structural Intermetallics and Composites; and Progress in New Plant Material.

For more information on IUMRS-ICA-97, contact Prof. Yoshimura Masahiro, Materials and Structures Laboratory, Tokyo Institute of Technology, 4259 Nagatsuta, Midori, Yokohama 226, Japan; phone 81-45924-5323; phone and fax 81-45-924-5358; e-mail iumrs1@rlem.titech.ac.jp.

\section{Member Societies \\ Communicate Across Borders}

MRS agreed to review proposals by adhering bodies of IUMRS to reprint $M R S$ Bulletin. Among the guidelines to be applied to proposal evaluations, MRS is to consider proposals that preserve the editorial and advertising content of the Bulletin as printed.

MRS-Russia publishes the journal Materials Science Aspects, as well as the abstracts and proceedings of conferences and seminars. MRS-Korea publishes the Korean Journal of Materials Research, with about 12 issues a year and approximately 170 papers per year. MRS-T publishes an international journal, Materials Chemistry and Physics, and conducts two materials science courses electronically via a website.

C-MRS publishes the Chinese Journal of Materials Science and Technology (in English) and the Chinese Journal of Materials Research (in Chinese). In 1994, CMRS published Materials Dictionary in Chinese, with four million words. The Materials Handbook (in Chinese) is expected to be published in 1998 .

C-MRS is starting a Science and
Technology Information Center which will issue the C-MRS Materials Electronic Bulletin. C-MRS has also been involved with a consulting project for the Chinese Academy of Engineering, "Present Situation of Materials Development in China and the Measures entering upon a New Century" (1996-1998) and with a research project entrusted by the State Science and Technology Commission of China, "Prediction on the Technology Development in China during the Next Ten Years" (1996-1998).

E-MRS and MRS-Russia have created an East/West network to help build MRSRussia. The network is operated in the framework of the European INTASProgramme. E-MRS has also set up a network with eight other national/federal and thematic materials societies in Europe based on a memorandum they signed at the Council of Europe, Strasbourg, in 1996. The memorandum calls for cooperation in areas such as conferences and education.

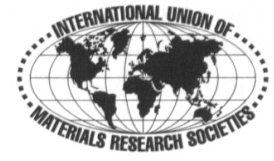

\section{ISTEC/MRS Presents Suitable Materials and Processing for HTS Applications}

The 1997 International Workshop on Superconductivity, which is the third joint International Superconductivity Technology Center/Materials Research Society Workshop, will be held June 15-18, 1997 in Big Island, Hawaii. S. Tanaka, Vice President of ISTEC, and Robert Hull, 1997 MRS President, are chairing the Workshop. The theme of this year's Workshop is "Suitable Materials and Processing for HTS Applications: Towards the Next Decade." The following sessions have been designed to teach the high-temperature supercon- ductor community in order to encourage the development of HTS materials:

- Processing of HTS Bulk

- Processing of HTS Wire, Tapes, and the Thick Films

- Crystal Growth Related to HTS Processing of Bulk and Films

- Thin Film Processing for RF Applications

- Fabrication and Control of HTS Junctions for Digital Circuits

- AC Losses, Vortex Dynamics, and Pinning

- SQUIDS and Sensor Applicatons.
S. Tanaka (ISTEC) will present a Special Lecture.

The proceedings of the Workshop will not be published; however, camera-ready extended abstracts will be published and distributed on-site.

For more information, contact Tetsuji Kobayashi, Director, International Affairs Dept., ISTEC 34-3, Shimbashi 1-chrome, Minato-ku, Tokyo 105, Japan; 81-3-34314004; fax 81-3-3431-4044; e-mail kokusai@ istec.mxa.meshnet.or.jp.

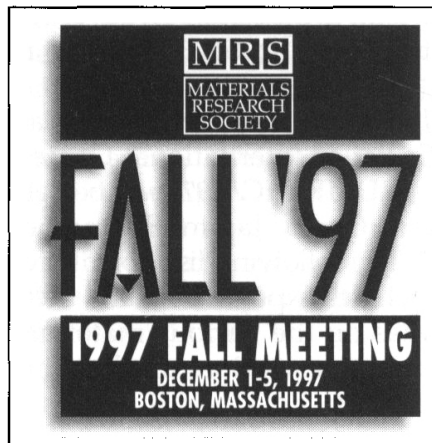

\author{
Harry A. Atwater \\ Thomas J. Watson Laboratory of Applied Physics \\ MS 128-95 \\ California Institute of Technology \\ Pasadena, CA 91125 \\ Phone 818-395-2197; Fax 818-795-7258 \\ haa@daedalus.caltech.edu \\ Dean $W$. Face \\ DuPont, Central Research and Development \\ P.O. Box 80304, Wilmington, DE 19880-0304 \\ Phone 302-695-9227; Fax 302-695-2721 \\ faced@esvax.dnet.dupont.com
}

Peter F. Green

Department of Chemical Engineering

CPE Building, University of Texas-Austin

Austin, TX 78712

Phone 512-471-3188; Fax 512-471-7681

green@che.utexas.edu

A. Lindsay Greer

Department of Materials Science and Metallurgy

Cambridge University, Pembroke Street

Cambridge CB2 3QZ, United Kingdom

Phone 44-1223-334308; Fax 44-1223-334567

alg13@cam.ac.uk 